\title{
Comparison of complete stress-strain curves of concrete using test prisms and test cylinders
}

\author{
E. Bezgodov and V. Shvedov ${ }^{*}$ \\ Moscow State University of Civil Engineering, Yaroslavskoye shosse, 26, Moscow, 129337, Russia
}

\begin{abstract}
Without concrete stress-strain curves based on the results of experiments obtained using test prisms and test cylinders it is difficult to evaluate the compliance of the ultimate strain of concrete with the peak load and the descending arm load at the level of $0.85 \mathrm{R}_{\mathrm{b}}$. In this paper, an attempt was made to experimentally verify curves $\sigma-\varepsilon$. Specimens made as one batch of the same concrete mix were tested using same methods. The test results showed that the difference in ultimate rates of strain is minor, and the analytical description of the curves obtained on prisms and cylinders corresponds to the results of testing not only at the peak load points and descending arm at the level of $0.85 \mathrm{R}_{\mathrm{b}}$, but also at intermediate values.
\end{abstract}

\section{Introduction}

To obtain complete stress-strain curves of concrete (complete CSSC) in different countries they use own specimens that differ in shape and height-to-width ratio, which can significantly affect the stress-strain characteristics, in particular the ultimate strain in compression, relevant peak load and the value of the descending arm of strain. The accepted ultimate strain in different countries differs significantly [1]. The curves of strain diagrams $\sigma-\varepsilon$ used to evaluate the stress-strain state differ as well.

According to the European Regulations, the stress-strain characteristics of concrete is assessed on test cylinders with a diameter-to-height ratio equal to $1 / 2$, i.e. on specimens with dimensions $150 \times 300,100 \times 200,71.4 \times 143 \mathrm{~mm}$. In the Russian standards, they use test prisms with a width-to-height ratio of equal to $1 / 4$, and thus the specimens have dimensions of $150 \times 150 \times 600,100 \times 100 \times 400,70.7 \times 70.7 \times 280 \mathrm{~mm}$. Studies [2] proved that the role of external friction during analysis of concrete strength is very significant. So, for example, prism strength coefficient $k_{b}=\frac{R_{b}}{R}$ can vary within $0.75: 0.9$ depending on the concrete class. Besides, to obtain a uniform strain field it is necessary to install measurement instrument at a distance equal to the width of the specimen (according to Saint-Venant's principle). Also, the height of the specimen can affect the deformations of the item. Studies [3-5] show that when testing concrete specimens for compression in a strain gauge tube, the graph of stress variance in the specimen with relative strains close to the ultimate has a descending arm. While numerous experiments conducted on different grades of concrete

Corresponding author: shwedov.vadim@yandex.ru 
using the method of complete stress-strain curves [6] under the supervision of I. M. Bezgodov proved that the descending arm exists only for the concrete with prismatic strength of 40-45 MPa. For the concretes of higher grades, it does not exist.

However, under the European norms, according to the results obtained when testing 1/2 ration cylinders the complete curve diagrams are described for the cylinders with a strength of up to $80 \mathrm{MPa}$. It should be noted that the Russian regulatory document SP 52-101-2003 designates the ultimate strain of concrete to equal $200 * 10^{-5}$ rel. u. European norms state an ultimate strain, both for the peak load and on the descending arm depending on concrete grade, and it turns out that the ultimate stress-strain performance for concrete of 20 and 100 MPa strength differs by 50\%. Studies conducted in paper [6] also indicate that the ultimate stress-strain performance differs depending on the concrete grade; this fact must be taken into account when calculating the stress-strain state of building structures.

\section{Methods}

In order to compare the stress-strain characteristics of concrete and estimate the ultimate deformability with the corresponding peak load and descending arm at $0.85 \mathrm{R}_{\mathrm{b}}$, test prisms of 10x10x40 cm and test cylinders with a diameter of $10 \mathrm{~cm}$ and a height of $20 \mathrm{~cm}$ were made simultaneously of the same concrete mixture. The concrete mixture was mixed in a gravitational-type concrete mixer, followed by vibrating the forms on the vibrating plate. The composition of the concrete mix with a ratio of components 1: 2.68: 4.23 was made based on portland cement M500 in the amount of $284 \mathrm{~kg} / \mathrm{m}^{3}$. The crushed stone with fraction size 5-10 and 10-20 and quartz sand were used. W/C $=0.64$. The cone slump of the concrete mixture was $3 \mathrm{~cm}$.

After stripping and storage for one month under normal conditions, the samples were cleaned, measured and weighed. Resistance strain gages with a base of $50 \mathrm{~mm}$ were glued on the surface of the sample.

The specimens were tested according to the method of complete stress-strain curves of concrete [7]. As the Russian normative documents do not contain GOST on the assessment of ultimate strains in compression, a set of methods to generate complete curves $\sigma-\varepsilon$, it does not allow introducing more reliable values of ultimate strains into the Russian norms, which reduces the reliability of calculations. However, there is the experience of generation of such curves in Russia [7, 8, 9] and world [10]. In accordance with these methods, the specimens were placed in a tube made of duraluminum alloy D16T. Lids were attached to the bottoms of the specimens. A gap was left between the upper end of the pipe and the lid, which made it possible to test the specimen according to standard methods and to determine the main characteristics of concrete $E_{b}$ and $v_{b}$. After the lid touched the tube a portion of the load was perceived by the tube. This method allows to determine the peak load and the value of the ultimate strain in compression. Further increase in the total load allows us to obtain a downward arm and to determine the relative strain corresponding to stressing $0.85 \mathrm{R}_{\mathrm{b}}$ on the downward arm. The stressing was made with a 5 -minute exposure stage. The instrument readings were taken at the beginning and at the end of exposure. Since main cracks appear after the peak load, as a result of which the resistance strain gages fall out, further measurement of the strain was carried out using dial indicators, which were installed in the tell-tale fixed in the device lids.

According to the results of the experiment Table 1 was compiled, where the stress-strain characteristics of concrete obtained on test prisms and test cylinders were presented, as well as curves $\frac{\sigma}{R_{B}}-\varepsilon$ Figures 1,2 
Table 1.

\begin{tabular}{|c|c|c|c|c|c|}
\hline Specimens & $R_{B} \mathrm{MPa}$ & $E_{B} \mathrm{MPa}$ & $v_{B}$ & $\varepsilon_{b_{0}}$ & $\varepsilon_{b_{0}}^{-0.85}$ \\
\hline Prism & 28.4 & $27.3^{*} 10^{3}$ & 0.207 & 204 & 284 \\
\hline Cylinders & 30.5 & $31.85 * 10^{3}$ & 0.202 & 207 & 290 \\
\hline
\end{tabular}

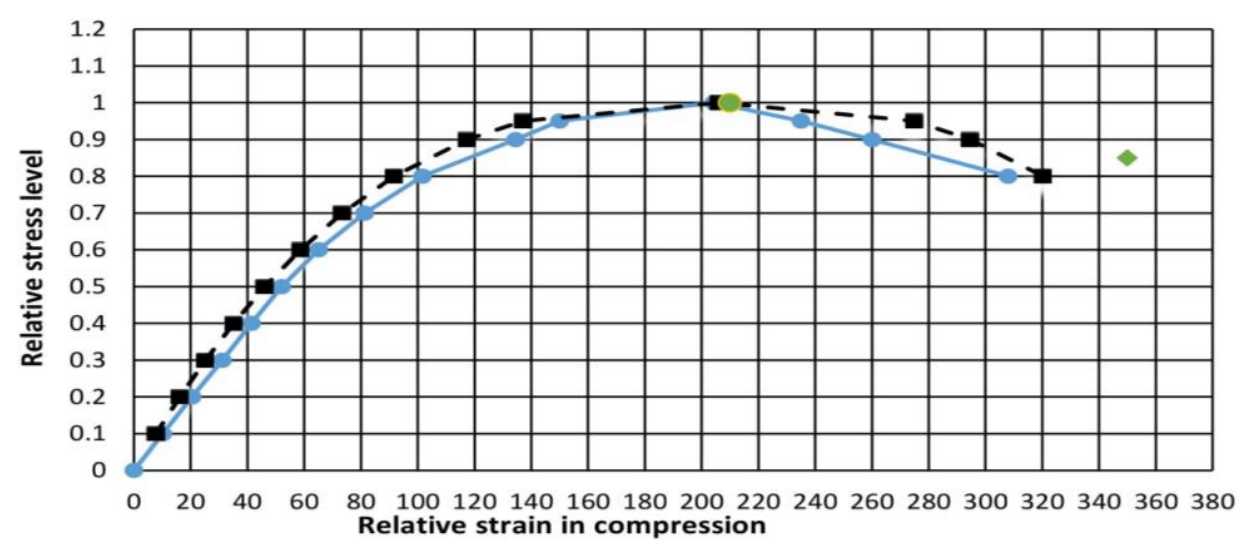

- Experimental values

- - Values obtained by formula (3)

- Strain values at peak load in EN1992 1-1

$\longrightarrow$ Strain values on the descending arm according to EN1992 1-1

Fig. 1. Curve $\frac{\sigma}{R_{B}}-\varepsilon$ for test prisms.

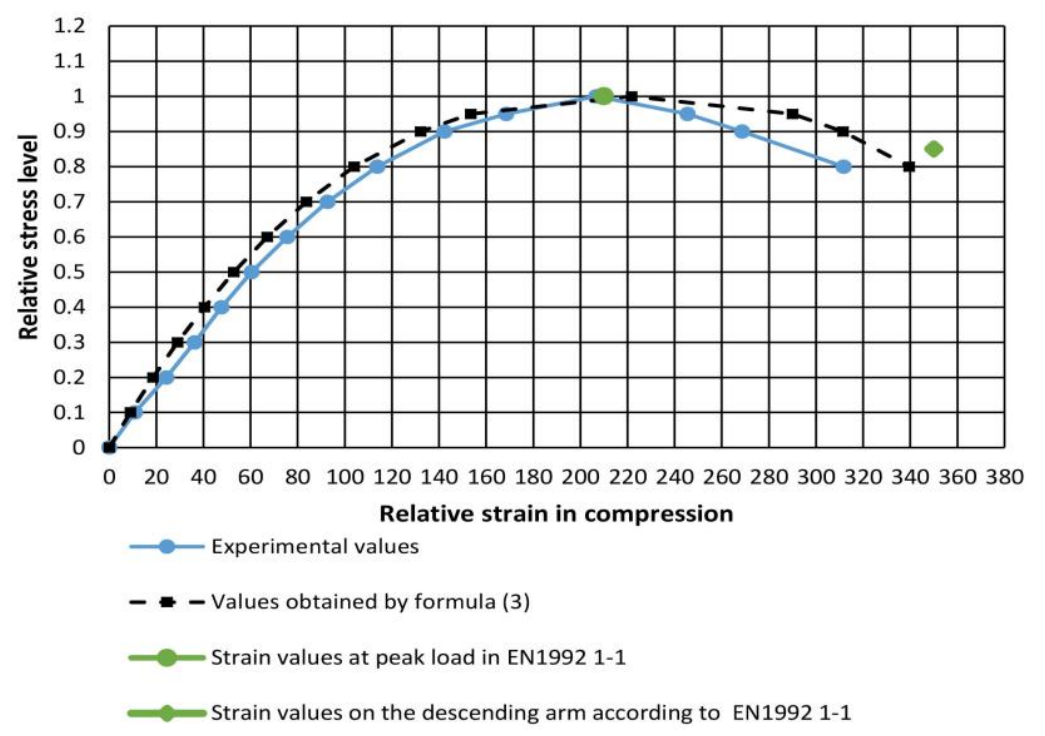

Fig. 2. Curve $\frac{\sigma}{R_{B}}-\varepsilon$ for test cylinders. 


\section{Results obtained}

As can be seen from Table 1 and Figures 1,2 , at peak load and load at $0.85 R_{b}$ level of the descending arm, the values of the ultimate strains of concrete obtained on test cylinders and test prisms are close. If we compare the prismatic and cylindrical strength, the cylinder strength is higher by $7.4 \%$. And the actual modulus of elasticity is higher by $16.7 \%$.

To calculate the stress-strain state of structures it is necessary to know not only the finite strain values, but also intermediate values. In article [1], the authors analyze the normative documents of different countries, where the calculations use complete stress-strain curves of concrete and ultimate strains as well as analytical description of these curves, which indicates the importance of studying these issues.

Paper [11] suggested equation (1) that makes it possible to evaluate intermediate values of strain depending on the relative stress level both on the ascending and descending part of the curve.

$$
\varepsilon_{\eta}=\varepsilon_{b_{0}}\left(1-\sqrt{1-\frac{\sigma}{R_{B}}}\right)
$$

-where $\varepsilon_{b_{0}}$ is ultimate strain, $\varepsilon_{b_{0}}=0,0225 * \sqrt[3]{\frac{R_{b}}{E_{b}}}$

It should be noted that when calculating the relative strains in the descending part sign should be replaced with + in parentheses.

The results of experiments [11] conducted on concrete with a prismatic strength of 23.3 $\mathrm{MPa}$ and a modulus of elasticity of $27.9 \mathrm{MPa}$ showed good convergence of this equation with the results of the experiments.

An attempt to describe our experiments with this formula confirmed its correctness when describing the curves obtained both on prisms and cylinders. Figures 1, 2 present the results of experiments and their analytical description. Comparing them with each other, we can make a conclusion of their satisfactory fit.

In current European standards (EN 1992 1-1) the relation between relative stress level and relative strain is expressed using formula (2), which is written as:

$$
\frac{\sigma_{c}}{f_{c m}}=\frac{K \eta-\eta^{2}}{1+(K-2) \eta}
$$

-where $\eta=\frac{\varepsilon_{c}}{\varepsilon_{c l}}$

$$
k=1,05 E_{c m} \times \frac{\left|\varepsilon_{c l}\right|}{f_{c m}}
$$

$\varepsilon_{c 1}$ - relative strain at the maximum (peak) stress value taken from the table.

Given that in this equation there is no parameter responsible for the nonlinearity of the strain curve, the accuracy of determining intermediate values is very difficult to assess. The authors of articles [12-15] also indicate that formula (2) has a number of drawbacks that can be avoided by introducing additional parameters.

Figure 1, 2 shows the points of the relative strain values for the peak load and descending arm taken from table (3.1) EN 1992 1-1, it should be noted that they correlate quite well with the results of our tests. 
As can be seen from Figure 1,2, formula (1) satisfactorily describes the results of the experiment. To estimate stresses at a given level of strain formula (1) can be transformed as (3).

$$
\sigma=R_{b}-\left(1-\frac{\varepsilon}{\varepsilon_{b_{0}}}\right)^{n} * R_{b}
$$

-where $\varepsilon$-current relative strain;

The last results of the experimental studies have shown that in order to correctly describe strain curves for concrete of different grades it is necessary to determine the quotient of the radicand in equation (3) in accordance with $\mathrm{R}_{\mathrm{b}}$ and $\mathrm{E}_{\mathrm{b}}$ using formula (4).

$$
n=3,5-\frac{R_{b}}{E_{b}}
$$

\section{Conclusions}

Thus, to compare the complete strain curves obtained on test prisms and test cylinders the experimental studies should be continued for various grades of concrete, which will allow correcting the equation and study the main differences for both the ascending and descending parts and determine the ultimate grades of concrete for which a descending arm exsist.

In addition, it is necessary to conduct long-term experiments to determine the creep of concrete in test prisms and test cylinders, which will assist to bridge the gap between the test methods under Russian and European standards.

\section{References}

1. Panfilov D, Pischulev A and Gamadetdinov K. 2014 Review of existing concrete strain curves under compression in domestic and foreign regulatory documents (Moscow: Industrial and civil construction) No. 3 Pp. 80-84.

2. Goncharov I. 1960 Strength of stone materials (Moscow: Stroyizdat) - L. Pp.124.

3. Murashkin G. and Pischlev A. 2009 The use of strain models to determine the bearing capacity of reinforced concrete bent elements with corrosion damage to the compressed area of concrete (Oriol: Izvestiya OriolGTU Construction and Reconstruction) No. 6.Pp. 36-42.

4. Murashkin G, Murashkin V and Panfilov D 2012 Application of software systems for refined calculation of deflections of reinforced concrete elements (Moscow: International Journal for Computational Civil and Structural Engineering) vol 8 No.4 Pp 89-95

5. Murashkin G, Panfilov D and Murashkin V. An Improved Technique of Calculating Deflections of Flexural Reinforced Concrete Elements Made of Conventional and HighStrenght Concrete. ( Usa: Jornal of Civil Engineering and Architecture) Vol 7 №2 (serial no 63) Pp 125-131.

6. Bezgodov I. 2015 On the question of evaluation of the ultimate strain of concrete under compression for various grades of concrete (Moscow: Concrete and reinforced concrete) No.5 Pp. 9-11.

7. Bezgodov I. and Levchenko P. 2013 On the question of the technique of obtaining complete stress-strain curves for concrete (Moscow: Concrete technologies) No.10 Pp. 34-36.

8. Bich P. 1987 Experimental and theoretical studies of supercritical characteristics of 
concrete (Moscow: Concrete and reinforced concrete) No.3 Pp 26-27.

9. Krol I. and Krasnovarsky R. 1986 Measurement of a complete strain diagram by the redistribution of forces (Measurements of the stress-strain properties of building materials, collection of scientific papers) (Moscow: VNIIFTRI) Pp 77-83.

10. Kiruchi M, Murai T and Komuro S. 1986 Stress-Strain curves of sintered fly ash aggregate concrete in compression (Tokio:Cement association of Japan general meeting) Review of the $40^{\text {th }}$ Pp 210-213.

11. Bezgodov I., Pakhratdinov A. and Tkachiov Y. 2016 Physical and mechanical characteristics of concrete on chips of crushed concrete (Moscow: Bulletin of $M G S U$ ) No.10. -Pp.24-34.

12. Karpenko N., Sokolov B. and Radaykin O. 2013 Analysis and improvement of the curvilinear stress-strain diagrams of concrete to calculate reinforced concrete structures based on the stress-strain modelstress-strain model (Moscow: Industrial and Civil Construction) -No.1 -Pp. 28-30.

13. Rimshin V., Krishan A. and Mukhametzyanov A. 2015 Formation of a strain diagram of uniaxially compressed concrete (Moscow: Bulletin of MGSU) No.6 -pp.23-31.

14.Zidonis I. 2007 A simple-to-integrate formula of stress as a function of strain in concreteand its description procedure (Mechanica) 4 (66). Pp 23-30.

15.Zidonis I. 2013 Strength calculation method for cross-section of reinforced concrete flexural member using curvilinear concrete stress diagram of EN-2 // 11th International conf on Modern Bulding Materials, Structures and Techniques. MBMST.Procedia Engineering. Vol. 57. Pp 1309-1818. 